\title{
Adhesive properties conferred by the plasminogen activator of Yersinia pestis
}

\author{
Zsuzsa Kienle, ${ }^{1,2}$ Levente Emödy, ${ }^{2}$ Catharina Svanborg ${ }^{3}$ and Paul W. O’Toole ${ }^{1 *}$ \\ 'Department of Medical Microbiology, University of Lund, Sölvegatan 23, S-223 62 Lund, Sweden \\ ${ }^{2}$ Department of Microbiology, University Medical School, Pécs, Hungary \\ ${ }^{3}$ Department of Clinical Immunology, University of Lund, Sölvegatan 23, S-223 62 Lund, Sweden
}

(Received 9 December 1991; revised 9 March 1992; accepted 13 April 1992)

\begin{abstract}
A genomic library of Yersinia pestis EV76c created in a cosmid vector was screened for clones capable of binding type IV collagen. An unexpectedly high number of such clones was observed. One recombinant plasmid was selected for further study, and the locus controlling collagen binding was mapped by subcloning, transposon mutagenesis and exonuclease digestion. The outer-membrane protein profiles of transposon insertion mutants were correlated with phenotype to implicate a $36 \mathrm{kDa}$ polypeptide in type IV collagen binding. Fine substructure restriction mapping and limited DNA sequence analysis showed the cloned locus to be identical to the locus (pla) for the plasminogen activator, previously characterized genetically and biochemically. The pla locus is resident on a $9.5 \mathrm{~kb}$ plasmid in wild-type $Y$. pestis strains. Curing of this plasmid resulted in negligible reduction in collagenbinding capacity, implying the existence of a chromosomally located determinant for collagen binding. The affinity of the plasminogen activator for collagen was relatively weak. When the cloned pla locus was introduced into $E$. coli, it conferred upon the cell the ability to bind to cells from a number of cell lines. Binding to glycolipids separated by thin-layer chromatography demonstrated that the receptor was a member of the globo-series of glycolipids. Since it has been reported that mutation of pla dramatically reduces virulence, we propose that this hitherto undescribed function of the gene product could contribute to the biological activities necessary for full virulence.
\end{abstract}

\section{Introduction}

The genus Yersinia contains three species pathogenic for man, $Y$. enterocolitica, $Y$. pseudotuberculosis and $Y$. pestis (Brubaker, 1991). All three species are capable of adhesion to and invasion of eukaryotic cells in vitro and in vivo (Portnoy et al., 1981; Vesikari et al., 1981). A common prerequisite for full pathogenesis is the virulence plasmid (Heesemann et al., 1984; Portnoy et al., 1983; Wolf-Watz et al., 1985). This plasmid encodes a number of proteins, many of which have been directly implicated in virulence (Bölin et al., 1982; Portnoy et al., $1981,1984)$. We have previously demonstrated that the major outer-membrane protein YAD A (formerly YOP 1) is responsible for specific binding to several types of collagen (Emödy et al., 1989). We also reported that $Y$. pseudotuberculosis has a second mechanism for

\footnotetext{
* Author for correspondence. Present address: Department of Biochemistry and Microbiology, University of Victoria, Victoria, BC, Canada V8W 3P6. Tel. (604) 721 7086; fax (604) 7218855.

Abbreviation: Pla, plasminogen activator protein.
}

collagen binding, presumably chromosomally encoded, since curing of the virulence plasmid was not sufficient to abolish collagen binding.

DNA hybridization studies have shown that $Y$.pestis and $Y$. pseudotuberculosis are extremely closely related, with an homology of $90 \%$ (Bercovier et al., 1980). One of the incentives for the present study was therefore to determine if $Y$. pestis also has a chromosomal determinant for collagen binding. In contrast to other members of the genus, $Y$. pestis normally harbours two plasmids other than the virulence plasmid. The larger of these is $110 \mathrm{~kb}$, and has been associated with the production of the murine toxin and Fraction 1 antigen (Protsenko et al., 1983; Brubaker, 1984). The small $9.5 \mathrm{~kb}$ plasmid is known to encode at least three polypeptides, responsible for pesticin, pesticin immunity, plasminogen activation and weak coagulase activity (Beesley et al., 1967; Brubaker \& Surgalla, 1962; Brubaker et al., 1965; Ferber \& Brubaker, 1981; Sodeinde et al., 1988). Plasmid-free strains lack all of these activities, and the ability to cause systemic infection following subcutaneous inoculation 
into guinea pigs or intraperitoneal injection into mice (Brubaker et al., 1965). The $9.5 \mathrm{~kb}$ plasmid of $Y$. pestis carrying the locus ( $p l a$ ) encoding the plasminogen activator has recently been characterized at the molecular level (Sodeinde \& Goguen, 1988, 1989; Sodeinde et al., 1988; McDonough \& Falkow, 1989). The loci encoding the pesticin and pesticin immunity were mapped, and a closely linked gene encoding a polypeptide with both plasminogen-activating and coagulase activity was also defined. It was proposed that proteolysis by the plasminogen activator ( $\mathrm{Pla}$ ) was responsible for the degradation of outer-membrane proteins encoded by the virulence plasmid when the bacterium is grown in vitro. Most recently, it has been reported that specific mutations inactivating the pla gene result in a 100000fold increase in $\mathrm{LD}_{50}$ values for $Y$. pestis after subcutaneous inoculation in mice (Goguen et al., 1990).

In this paper, we present data showing that the pla locus, when cloned in Escherichia coli, conferred the ability to bind to type IV collagen. Additionally, it allowed laboratory strains of $E$. coli to adhere to eukaryotic cells grown in tissue culture. In an in vitro binding assay, it was shown that the Pla protein mediated binding to a range of glycolipids in which the globoside series are dominant components. Binding to immobilized collagen IV and cultured cells could be substantially reduced by treatment with galactosidase, showing that these properties may be mediated by a lectin-like interaction with carbohydrate molecules covalently linked to the collagen molecule.

\section{Methods}

Bacterial strains. The Yersinia pestis strain EV76c (Rosquist et al., 1988 ) is a former vaccine strain lacking the large virulence plasmid. A derivative of this strain lacking the $9.5 \mathrm{~kb}$ plasmid encoding Pla was provided by $\mathrm{H}$. Wolf-Watz, Department of Cell and Molecular Biology, University of Umeå, Sweden. Yersinia pseudotuberculosis strain YPIII was described by Bölin et al. (1982). E. coli strains TB1 and HB101 were employed as hosts for recombinant plasmids (YanischPerron et al., 1985; Bachmann, 1972). Culture conditions for Yersinia were as previously described (Emödy et al., 1989).

Recombinant DNA methodology. Standard molecular cloning techniques were employed (Sambrook et al., 1989). Total genomic DNA of $Y$. pestis was prepared according to the method of Hull et al. (1981). The cosmid vector pJB8 was described by Ish-Horowicz \& Burke (1981). The plasmid vectors pUC18 and pUC19 (Yanisch-Perron et al., 1985) and pK18 and pK19 (Pridmore, 1987) were routinely employed. Sequence analysis was performed on denatured plasmid templates using $\mathrm{T} 7$ polymerase (US Biochemicals) in the Sanger chain termination technique. Primers consisted of the forward and reverse sequencing primers on each side of the multiple cloning site in the plasmid vector. Transposon mutagenesis by $\operatorname{Tn} 5$, using $\lambda 467$ as donor, was performed as described by Coleman \& Foster (1981).
Collagen binding assays. Bovine type I collagen was from Collagen Corporation, Palo Alto, Calif., USA, and murine type IV collagen was from Collaborative Research Inc., Bedford, Mass, USA. A tube assay for collagen binding by bacterial cells was employed, according to standard protocols (Emödy et al., 1989). Specificity of type IV collagen binding in this assay was determined using a panel of serum proteins as previously described (Emödy et al., 1989). As an alternative, a quantitative solid phase assay was developed. Wells of standard ELISA plates (Nunc, Denmark) were coated by overnight incubation at $4{ }^{\circ} \mathrm{C}$ with collagen at a concentration of $20 \mu \mathrm{g} \mathrm{ml}^{-1}$. The plates were then washed three times with phosphate-buffered saline (PBS; 0.1 M-sodium phosphate, $\mathrm{pH} 7.2$ ) and blocked with bovine serum albumin (BSA ; $2 \%$, $\mathrm{w} / \mathrm{v}$, in PBS). A standardized bacterial suspension $\left(10^{9}\right.$ bacteria $\left.\mathrm{ml}^{-1}\right)$ was prepared from cells grown overnight at $37^{\circ} \mathrm{C}$ on colonization factor antigen agar (CFA agar; Nowicki et al., 1986) and $0.1 \mathrm{ml}$ of this suspension was added to the wells. After $90 \mathrm{~min}$ at $37^{\circ} \mathrm{C}$ the wells were washed repeatedly with PBS, then fixed by adding $2 \%(\mathrm{v} / \mathrm{v})$ formalin in PBS for $1 \mathrm{~min}$. Attached bacteria were stained for $20 \mathrm{~min}$ with crystal violet $(0.13 \%$ crystal violet, $5 \%, v / v$, methanol in PBS). The plate was then washed three times with PBS, allowed to dry in air, and bound dye released by addition of $200 \mu 1 \operatorname{SDS}(1 \%, \mathrm{w} / \mathrm{v}, \mathrm{SDS}, 5 \%, \mathrm{v} / \mathrm{v}$, ethanol in PBS) per well, with $20 \mathrm{~min}$ incubation for full lysis. Absorbance at $595 \mathrm{~nm}$ was read by automated ELISA plate reader (LKB), and relative values calculated with respect to a positive parental strain. Alternatively, tritium-labelled bacterial cells could be used as described below for the cell adhesion assay.

Solid phase assay for collagen binding. Wells of microtitre plates (8well strip plates, Costar) were coated with $100 \mu \mathrm{l}$ of a solution of collagen IV $\left(20 \mu \mathrm{g} \mathrm{ml}^{-1}\right.$ in PBS). The wells were then washed with PBS containing $0.2 \%(\mathrm{w} / \mathrm{v}) \mathrm{BSA}$, and blocked by incubation for $1 \mathrm{~h}$ with PBS containing $2 \%(\mathrm{w} / \mathrm{v})$ BSA. A standard curve for coating efficiency was constructed, based upon quantification of radiolabelled collagen bound to the wells. Following blocking, wells were washed three times with PBS containing $0.2 \%$ BSA. Increasing amounts of Pla, radioiodinated according to published procedures (Emödy et al., 1989), were added to a series of coated wells in a constant volume of $100 \mu \mathrm{l}$, and incubated for $1 \mathrm{~h}$ at ambient temperature. Wells were then washed five times with PBS containing $0.2 \%$ BSA. The amount of Pla protein bound was extrapolated from counts of retained radioactivity with reference to the specific activity of the labelled protein added. The background value was subtracted, based upon non-specific retention of Pla by wells coated with BSA.

Cloning a Y.pestis collagen receptor. A gene library was constructed in the cosmid vector pJB8 by ligating EV76c DNA which had been partially digested with Sau3A to vector DNA linearized with BamHI. The genomic DNA digest was adjusted to yield products predominantly in the $20-40 \mathrm{~kb}$ range. The ligated DNA was packaged in vitro (Packagene vials, Promega), and transfected into strain HB101. The yield was $1 \times 10^{5}$ recombinants per $\mu \mathrm{g}$ ligated DNA. Plates containing approximately 300 colonies were replicated onto nitrocellulose filters which were then treated as for normal colony blotting (Helfman et al., 1983). The filters were incubated in a solution of radiolabelled collagen IV, radio-iodinated as described previously (Emödy et al., 1989). After $2 \mathrm{~h}$ incubation, the filters were washed for three $10 \mathrm{~min}$ periods in blotting buffer, dried, and subjected to autoradiography. Colonies appearing positive in this assay were picked, and their phenotype was verified by both tube and solid-phase assays described above. One such recombinant was chosen for further study, and the cosmid it contained designated $\mathrm{pC} 4001$

Subcloning and localization of the collagen receptor. From the original recombinant insert in pJB8 of approximately $23 \mathrm{~kb}$, a variety of progressively smaller fragments carrying the putative receptor gene were subcloned, using collagen binding to monitor each new 


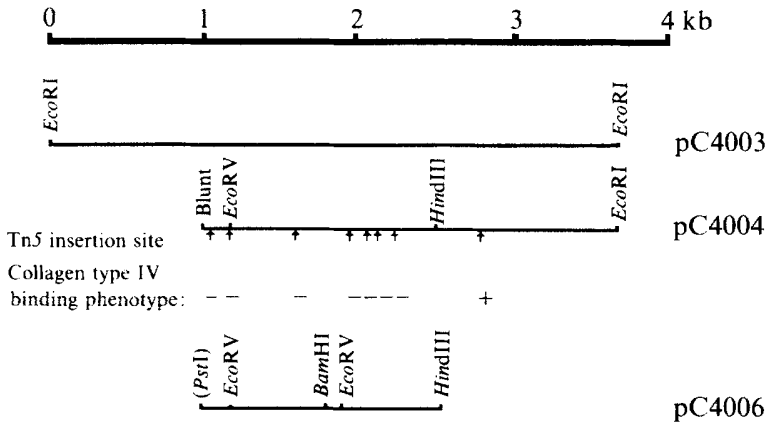

Fig. 1. Restriction maps of the inserts in recombinant plasmids pC4003, pC4004 and pC4006. Arrowheads under pC4004 indicate the site of insertion of transposon $\mathrm{Tn} 5$, to produce the phenotypes indicated. The restriction site in parentheses originated in a plasmid vector.

recombinant. The plasmid pC4003 in this series had a $3.6 \mathrm{~kb}$ EcoRI fragment. A set of deletions was created from each end of the insert using controlled exonuclease digestion by exonuclease BAL31. Among the smaller plasmids retaining the collagen-binding phenotype was pC4004, which had an insert of $2.4 \mathrm{~kb}$. This plasmid was subjected to mutagenesis by $\mathrm{Tn} 5$. Mapping of the site of insertions giving rise to loss of collagen binding implicated a region of approximately $1500 \mathrm{bp}$ in expression of the collagen receptor, centered around a unique Bam HI restriction site (Fig. 1). This region could be conveniently subcloned on a $1.2 \mathrm{~kb}$ HindIII-PstI fragment in pUC19, generating the recombinant plasmid pC4006 (Fig. 1).

Membrane profile analysis. Outer membranes of transposon insertion mutants and parental strains were prepared according to the procedure of Filip et al. (1973). Membrane fractions were then analysed by conventional SDS-PAGE (Laemmli, 1970). When required, Western immunoblotting was performed upon proteins separated by SDSPAGE and transferred to nitrocellulose according to standard methodologies (Sambrook et al., 1989).

Fibrinolysis assay. Fibrinolytic activity was detected by the method of Beesley et al. (1967). In brief, samples to be tested were spotted onto the surface of a fibrin plate and incubated overnight at $37^{\circ} \mathrm{C}$. Zones of fibrinolysis were visualized by clearing of the opacity in the plate, and could be compared relatively by measurement of zone diameter.

Eukaryotic cells and cell attachment assay. The McCoy cell line used was from Flow Laboratories (UK), and is derived from synovial fluid. Caco-2 intestinal epithelial cells were described by Finlay \& Falkow (1990). The A498 cell line was from the American Type Culture Collection (ATCC HTB 44). Cells were cultured in MEM-glutamine medium (Flow Laboratories; Eagle's minimum essential medium supplemented with $2 \mathrm{~mm}$-glutamine) incorporating $10 \%(\mathrm{v} / \mathrm{v})$ foetal calf serum. A total of $3 \times 10^{5}$ cells, in $3 \mathrm{ml}$ of culture medium, were added to $35 \mathrm{~mm}$ tissue-culture dishes and incubated in a $\mathrm{CO}_{2}$ incubator for $24 \mathrm{~h}$. The dishes were then washed three times in Dulbecco's PBS (DPBS; Flow Laboratories), and $2 \mathrm{ml}$ of a bacterial suspension $\left(5 \times 10^{8}\right.$ cells $\mathrm{ml}$ in DPBS) was added. Incubation was continued for a further $3 \mathrm{~h}$ in the $\mathrm{CO}_{2}$ incubator, the cells were washed three times with PBS, after which the cells were fixed in methanol and stained with Giemsa stain. Attachment was quantitatively evaluated by microscopy, counting bacteria per eukaryotic cell for at least 100 cells. For rapid qualitative analysis, counting with a cut-off value for positivity could be used (i.e. 10 bacterial cells per eukaryotic cell).

An alternative method employed radiolabelled bacterial cells, grown overnight in LB broth incorporating appropriate antibiotic and [methyl ${ }^{3} \mathrm{H}$ ]thymidine $\left[20 \mu \mathrm{Ci} \mathrm{ml}^{-1}\left(740 \mathrm{kBq} \mathrm{ml}^{-1}\right)\right]$. The cells were washed twice in PBS, and attachment performed as above with the exception that the eukaryotic cells were cultured in EIA/RIA strips (8well strip plates; Costar), facilitating cutting out for counting. Confluent cell cultures were selected to minimize background adsorption. Counting of bound radioactivity was performed with the Beckman LS1800 system

Isolation of the putative collagen-binding protein. An outer-membrane fraction of $E$. coli strain TB1 harbouring pC4003 was prepared, and extracted with Triton-X100 following standard procedures (Owen, 1985). The Triton-insoluble fraction was electrophoresed on a preparative SDS-polyacrylamide gel $(12.5 \%$, w/v, acrylamide). The $36 \mathrm{kDa}$ species of the Pla protein was localized by staining a strip of the gel, and the corresponding area was excised from the main gel. The gel matrix was macerated by repeated passage through a syringe, and protein eluted by overnight gentle shaking in PBS at $4{ }^{\circ} \mathrm{C}$. The suspension was clarified by centrifugation at $45000 \mathrm{~g}$ for $30 \mathrm{~min}$ and the protein content established (Bio-Rad Protean assay).

Immunization. Antiserum to the $Y$. pestis collagen-binding protein was generated by immunization of rabbits (New Zealand White) with the $36 \mathrm{kDa}$ polypeptide isolated by preparative gel electrophoresis. The excised band was macerated in PBS to form a homogeneous suspension, then mixed with Freund's complete adjuvant, and administered subcutaneously. After 3 weeks, a booster injection of the original suspension, without addition of adjuvant, was injected. Serum was collected after a further three weeks, and had an ELISA titre of 4000 against the immunogen, using an absorbance value equal to twice that of a negative control as cut-off.

Glycolipid extractions. A small scale procedure which yielded material suitable for thin-layer chromatography (TLC) from low amounts of starting material was employed as described by Linstedt $e t$ al. (1991).

In vitro adhesion assay. A standard assay was employed (Linstedt $e t$ $a l ., 1991)$. Briefly, glycolipids were first separated on Kieselgel 60 , alumina-backed HPTLC plates (Merck) using chloroform/methanol/ water $(60: 35: 8$, by vol.). Bacteria were labelled by overnight growth in Luria broth containing $1 \mathrm{mM}-\mathrm{CaCl}_{2}$ and $50 \mu \mathrm{Ci}(1.85 \mathrm{MBq})\left[{ }^{35} \mathrm{~S}\right] \mathrm{meth}$ ionine, washed repeatedly, and then incubated with the thin layer chromatogram which had been blocked by incubation with $2 \% \mathrm{BSA}$ in PBS. After $2 \mathrm{~h}$, the plate was washed repeatedly in PBS, dried and autoradiographed.

Glycosidase treatment. Glycosidases were from Sigma. $\beta$-Galactosidase, endoglycosidase $H$, endoglycosidase $F$ and sialidase treatment of immobilized type IV collagen and cultured eukaryotic cells was performed as follows. The coated and blocked wells were washed twice with PBS for the $\beta$-galactosidase, or acetate buffer $(0 \cdot 1 \mathrm{M}, \mathrm{pH} 5.5)$ for the endoglycosidases and sialidase. Enzyme was added to a final concentration of $10 \mathrm{U} \mathrm{ml}^{-1}$ in PBS for $\beta$-galactosidase, or $10 \mathrm{mU} \mathrm{ml}^{-1}$ in acetate buffer for endoglycosidase $H$, endoglycosidase $F$ and sialidase. All reactions were performed at $37^{\circ} \mathrm{C}$ for $2 \mathrm{~h}$, and were terminated by repeated washing in PBS. A normal binding assay was then performed.

\section{Results}

\section{Cloning and localization of a determinant encoding $a$ collagen binding protein}

A gene library constructed in the cosmid vector pJB8 was screened for collagen binding clones by colony blotting 


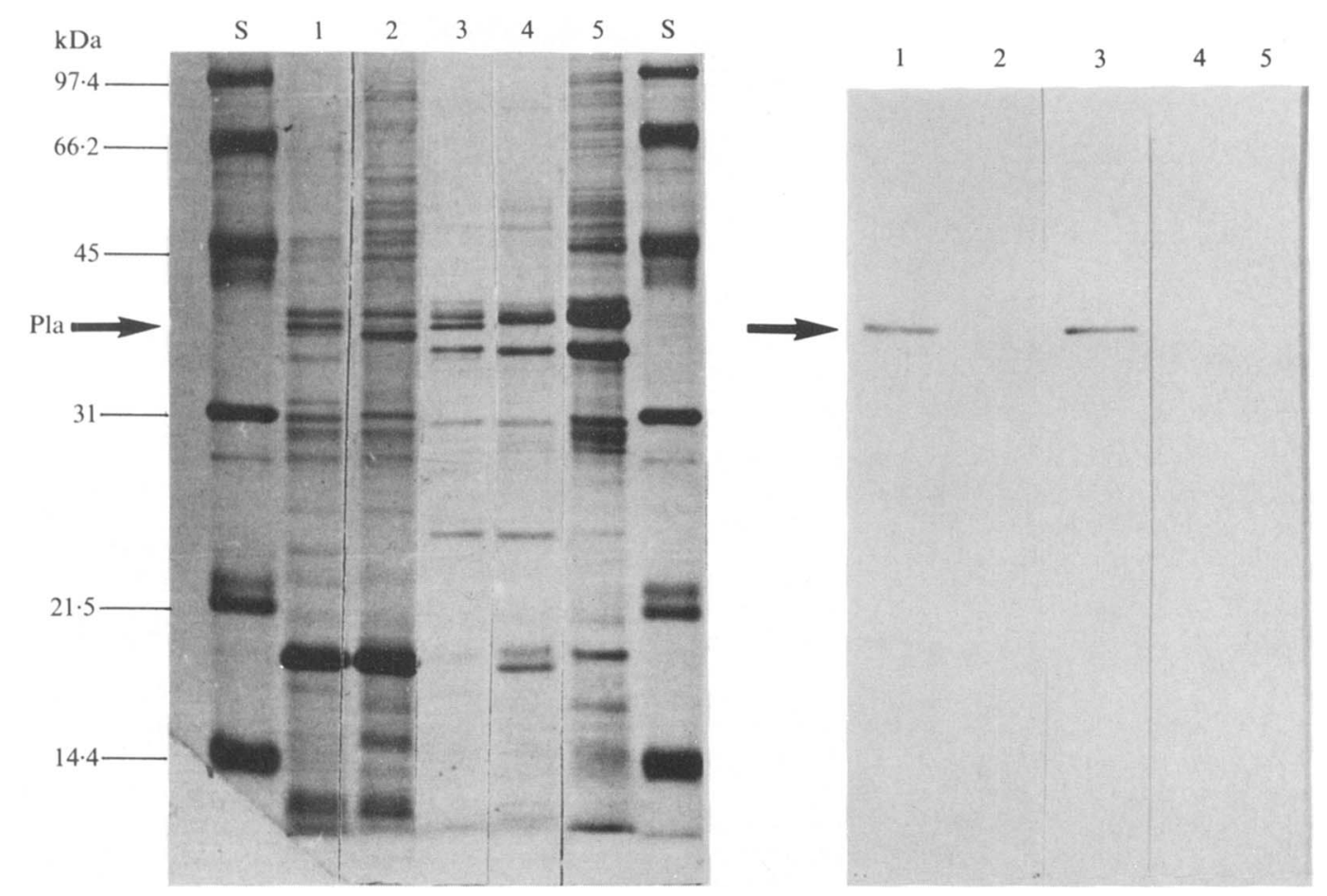

Fig. 2. SDS-PAGE of outer-membrane preparations, and corresponding Western immunoblot, of $Y$, pestis, E. coli cells harbouring the cloned pla gene, and deletion and transposon mutants in the cloned locus. The left-hand panel shows the gel after staining with Coomassie brilliant blue; the right-hand panel shows the result of transferring an identical gel to nitrocellulose and immunoblotting with specific antiserum against the $Y$. pestis plasminogen activator $(\mathrm{Pla})$. The Pla polypeptide visible in lanes 1 and 3 is arrowed. Lanes: $\mathrm{S}$, molecular mass standards of indicated size; 1, Y. pestis EV76c;2, Y. pestis EV76 lacking the Pla plasmid; 3, E. coli TB1/pC4006; 4, representative BAL31-generated deletion mutant of pC4003 which did not bind collagen; 5, E. coli TB1/pC4004::Tn5.

with radiolabelled type IV collagen. The Sau3A-digested genomic DNA to be cloned was not size fractionated, but digestion conditions had been optimized for production of fragments in the $20-40 \mathrm{~kb}$ range. Collagen-binding clones were detected at a rate of about 1 per 100 clones, i.e. about three times the expected frequency for a single copy locus in such a cloning system. One primary clone, designated pC4001, had an insert of around $23 \mathrm{~kb}$ and was chosen for further study. This recombinant cosmid directed the expression of collagen binding as measured in both tube and solid-phase assays. By a series of successive subcloning experiments, the relevant sequence was reduced to $3.6 \mathrm{~kb}$ of $Y$.pestis DNA cloned in pK 18, called pC4003 (Fig. 1). The insert size was further reduced by progressive deletion with exonuclease BAL31 to generate pC4004, which harboured a $2.4 \mathrm{~kb}$ fragment. This plasmid was subjected to transposon mutagenesis by Tn5, using a suicide phage delivery system. Phenotypes arising from transposon mutagenesis of the cloned DNA were checked by collagen-binding assays. Physical mapping of the site of Tn5 insertion in mutants failing to bind collagen implicated a region of about $1500 \mathrm{bp}$ centred around a unique BamHI site in the cloned fragment. This area could be conveniently subcloned into pUC19 on a $1200 \mathrm{bp}$ fragment generated by digestion with the enzymes $P$ st I and HindIII, creating the recombinant plasmid pC4006 (Fig. 1).

\section{Identification of the cloned collagen binding protein}

The outer-membrane protein profiles of parental collagen-binding clones, transposon insertion mutants and BAL31 deletion mutants were compared (Fig. 2). From consideration of the phenotypes of these derivatives, it was readily apparent that a prominent polypeptide migrating with an apparent molecular mass of $36 \mathrm{kDa}$ was present both in $Y$.pestis and collagen-binding E. coli clones, but was absent in $Y$. pestis lacking the $9.5 \mathrm{~kb}$ plasmid and $E$. coli transposon-insertion mutants which did not bind type IV collagen. Since the outer-membrane proteins of $Y$. pestis are relatively well characterized, and the polypeptide we were focusing on was a conspicuous component, we investigated the possibility that the collagen-binding protein had been previously identified or analysed. Fine structure restriction mapping of the cloned fragment in $\mathrm{pC} 4006$, followed by comparison with the literature for $Y$. pestis outer-membrane proteins, indicated similarity to the locus encoding the plasmino- 


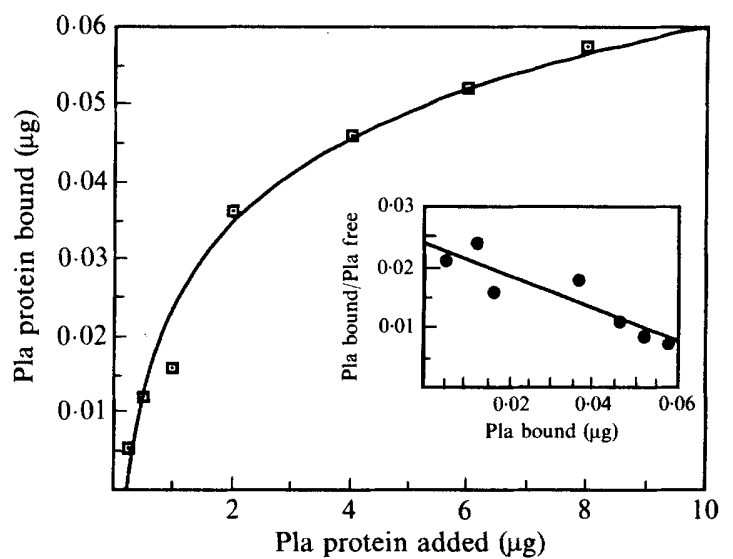

Fig. 3. Analysis of the binding of radio-iodinated $Y$. pestis plasminogen activator to immobilized type IV collagen. Inset: Scatchard plot of the binding data.

gen activator (pla; Sodeinde \& Goguen, 1988). Limited DNA sequence analysis (about 300 residues from both $5^{\prime}$ and $3^{\prime}$ ends of the coding sequence) of the termini of the cloned fragment in pC4006 confirmed identity with the published sequence for the pla locus. Assay of whole cells of $E$. coli harbouring pC4006 (and parental plasmids) for fibrinolytic activity confirmed the presence of plasminogen-activating activity. The insert in pC4006 was used as a probe in Southern hybridization experiments. When digested genomic DNA was probed, only the plasmidderived $E c o$ RI fragment of approximately $7.0 \mathrm{~kb}$ present in EV76c hybridized (data not shown).

\section{Quantification of collagen binding by solid-phase assay}

Using a standardized coating system, $43 \mathrm{ng}$ of type IV collagen was bound per well of the microtitre strips employed. Addition of increasing amounts of radioiodinated Pla to these wells demonstrated that binding was saturable (Fig. 3). Scatchard analysis of the data (Scatchard, 1949) yielded a linear plot, indicating a single type of interaction. A dissociation constant of $1 \mu \mathrm{M}$ was derived from this data.

\section{Adhesive properties conferred by the plasminogen activator}

Laboratory $E$. coli strains did not exhibit significant binding to cultured cells of the McCoy cell line, but introduction of the cloned pla gene was sufficient to allow such adhesion (Fig. 4). Analysis of parental $Y$. pestis strains and $E$. coli harbouring the series of recombinant plasmids generated in this study showed that there was an absolute correlation between positivity in the colla- gen-binding assay and the ability to attach to McCoy cells. Adhesion could also be seen with other cell lines including Hep2. The binding activity mediated by Pla was specific for type IV collagen, since tube assay with type I collagen and a panel of serum proteins was consistently negative (data not shown).

Carbohydrate residues are established target structures for a variety of prokaryotic adhesion mechanisms. To test their possible involvement in this system, immobilized collagen and McCoy cell monolayers were treated with a small selection of specific endoglycosidases prior to performance of the adhesion assay. Significant inhibition was achieved only with $\beta$-galactosidase in either assay (Table 1). Endoglycosidases $\mathrm{F}$ and $\mathrm{H}$ were equally poor inhibitors of adhesion to $\mathrm{McCoy}$ cells, while the latter had almost no effect on binding to immobilized collagen. Sialidase had no inhibitory affect in either assay.

Table 1. Effect of glycosidase treatment on Pla-mediated binding to McCoy cells and immobilized type IV collagen

Inhibition values are percentage reduction in binding after treatment with indicated substance relative to binding in the absence of any treatment. The indicator strain was $E$. coli TB1/pC4006.

\begin{tabular}{lcc}
\hline \hline & \multicolumn{2}{c}{ Percentage inhibition of binding by Pla to: } \\
\cline { 2 - 3 } Enzyme & McCoy cells & Type IV collagen \\
\hline Endoglycosidase F & 15 & 10 \\
Endoglycosidase H & 17 & 0 \\
$\beta$-Galactosidase & 46 & 58 \\
Sialidase & 17 & 0 \\
\hline \hline
\end{tabular}

Table 2. Binding of E. coli cells with or without the cloned pla gene to mammalian glycolipids

A standard overlay assay of glycolipids separated by thin-layer chromatography, and probed with radiolabelled bacteria, was performed.

\begin{tabular}{lcc}
\hline \hline & \multicolumn{2}{c}{ Binding to E. coli: } \\
\cline { 2 - 3 } Compound & HB101 & $\begin{array}{c}\text { HB101/pC4006 } \\
\left(\mathrm{Pla}^{+}\right)\end{array}$ \\
\hline Total glycolipid extract (A498 cells) & - & + \\
Total glycolipid extract (Caco-2 cells) & - & + \\
Total glycolipid extract, meconium & - & - \\
Neutral glycolipid (pig erythrocyte) & + & + \\
Acidic glycolipid (pig erythrocyte) & - & + \\
Lactosylceramide & - & + \\
Total glycolipid, uroepithelial cells & - & + \\
Total neutral extract dog mucosum & + & + \\
Buccal extract & + & + \\
Globoside & - & + \\
\hline
\end{tabular}



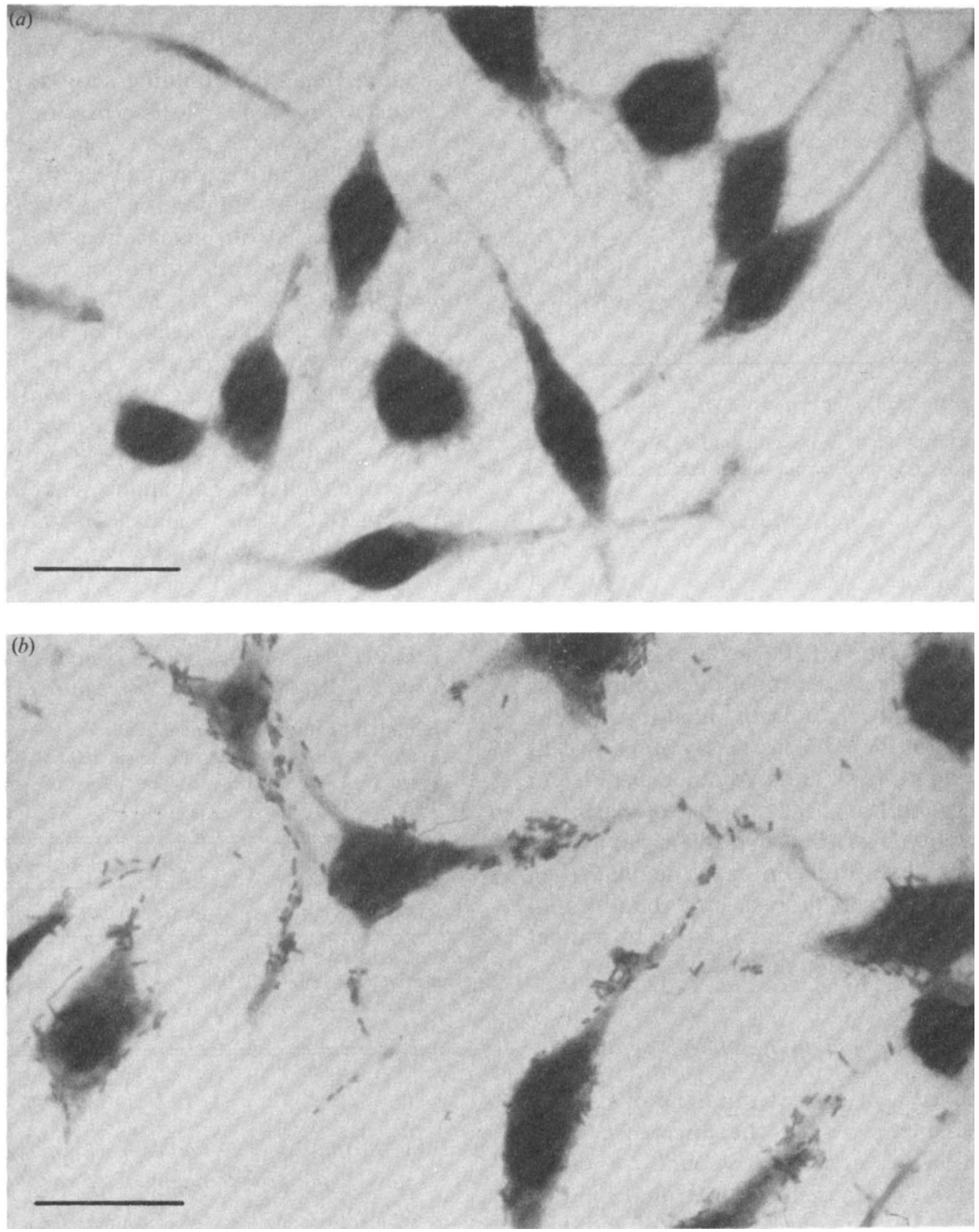

Fig. 4. Adhesion to cultured eukaryotic cells mediated by the cloned pla locus. Monolayers of McCoy cells were incubated with cells of $E$. coli harbouring the vector plasmid pUC19 (a) or the recombinant plasmid pC4006 which has the cloned pla gene (b). E. coli cells were stained with Giemsa stain. Bars, $20 \mu \mathrm{m}$.

\section{Identification of the receptor for Pla}

In a standard in vitro assay for glycolipid binding, cells harbouring the pla gene bound to the total glycolipid extracts from a number of tissue sources, as well as neutral extracts from cells rich in globotetraosylceramide (globoside). Cells carrying the cloned pla locus also bound to purified globoside. These novel bindings were in addition to the limited background of compounds recognized by the host strain. (Table 2).

\section{Discussion}

The objective of the present study was to use molecular cloning techniques to identify a chromosomally encoded collagen-binding mechanism in $Y$.pestis. The surprising result of this investigation, however, has been to implicate an outer-membrane protein of established function as a possible adhesin. The process of subcloning, deletion and transposon mutagenesis unequivocally linked the collagen-binding phenotype to a region of 
cloned DNA spanning about $1500 \mathrm{bp}$, which was shown to encode the plasminogen activator, Pla. The cloned collagen-binding protein had the fibrinolytic activity expected, and limited DNA sequence determination revealed absolute identity with the published data.

Sodeinde \& Goguen (1989) also reported the existence of an open reading frame overlapping pla on the complementary strand, which could encode a protein of 48 amino acid residues. Our finding that the isolated $36 \mathrm{kDa}$ Pla polypeptide bound to collagen supports the probability that it is this protein which is responsible for the activities associated with the cloned fragment. However, it does not unequivocally rule out the possibility that the gene product of the second smaller open reading frame might be responsible for, or contribute to, the adhesive properties we have observed in this study.

Introduction of the cloned pla locus into E. coli conferred upon the recipient the ability to bind to both type IV collagen and to cultured eukaryotic cells. Evidence provided by glycosidase treatment supports the hypothesis that specific sugar recognition is the common denominator for these two binding properties. A unique feature of type IV collagen is the presence of complex carbohydrate, attached through asparagine and hydroxylysine residues in the helical region (Glanville et al., 1985, 1987; Schwarz et al., 1986). The function of these substitutions is unknown. Their presence could well explain the specificity of Pla recognition of type IV collagen from among other collagen types.

Neither endoglycosidase $\mathrm{H}$ nor $\mathrm{F}$ dramatically reduced collagen binding or McCoy cell binding. Highest inhibition was achieved with $\beta$-galactosidase, implicating galactose somewhere in the structure recognized. Further supportive evidence for the importance of sugar residues was provided by a standard glycolipid attachment assay. Cells expressing Pla bound to total glycolipid from two cell lines (known to be rich in globoside), and from uroepithelial cells. Finally, purified globoside was recognized by the bacterial lectin, possibly indicating that this is the target in eukaryotic cells. As yet, however, there is insufficient data to pinpoint an homologous structure in the carbohydrate content of collagen type IV. The globoside recognized by $\mathrm{Pla}$ has the structure GalNAc $\beta 1-3 G a l \alpha 1-4$ Gal $\beta 1-4$ Glc $\beta 1-1$ Ceramide (Leffler \& Svanborg-Edén, 1981) while the hydroxylysinelinked carbohydrate of collagen type IV has the structure Glc $\alpha 1-2 \mathrm{Gal} \beta 1-5 \mathrm{Hydroxylysine}$ (Spiro \& Spiro, 1970). Further experiments are underway to elucidate the exact sugar specificity of the lectin-like activity of Pla.

Scatchard analysis of the interaction between the Pla polypeptide and immobilized type IV collagen indicated an apparent dissociation constant of $1 \mu \mathrm{M}$. Compared to bacterial binding of serum proteins, exemplified by nonimmune binding of streptococci and staphylococci to immunoglobulin (reviewed by Boyle, 1990), this affinity is very low (about three orders of magnitude lower). Rather than the high affinity protein-protein interactions which Fc-binding mechanisms seem to typify, the Pla-mediated binding to type IV collagen seems to be a lectin-like interaction of much lower avidity.

The bindings to type IV collagen, separated glycolipids and cultured eukaryotic cells described in this study are reproducible interactions which can be quantitatively monitored in vitro. Whether they have a role in the process of pathogenesis in vivo remains to be proven. Circumstantial evidence suggesting they might is, however, already available. Goguen et al. (1990) reported that mutation in the pla locus resulted in decreased virulence for $Y$. pestis when administered subcutaneously in mice, but not intravenously. It may arguably be important for establishing a locus of infection that the bacterium be able to bind to connective tissue components and/or eukaryotic cells. In a number of bacterial-host interaction systems, glycolipids are important recognition targets for establishing infection (Karlsson, 1987; Ofek \& Sharon, 1990). Additionally, the ability to bind basement membrane components could be important in plague, when colonization of the lungs facilitates dissemination of the disease.

One conclusion of this study is that a protein with a function established in the literature as being plasminogen activation has the additional ability to mediate binding to the basement membrane component collagen type IV. We could not detect significant homology between the sequences of plasminogen and collagen which might have suggested recognition by the Pla polypeptide of shared primary amino acid sequences. We have preliminary evidence showing that the two bindings are biochemically distinct (Z. Kienle \& P. W. O'Toole, unpublished). There are, however, precedents for such dual functionality, namely the binding to plasminogen and laminin by S-fimbriae of $E$. coli (Parkkinen \& Korhonen, 1989; Virkola et al., 1991), and plasminogen activation by fimbriated Salmonella enteritidis (Lahteenmaki \& Korhonen, 1991). In the former example, R. Virkola and co-workers used a reconstituted basement membrane (Matrigel) to demonstrate increased invasiveness by the S-fimbriated strain in the presence of added plasminogen. The authors propose a novel mechanism for basement membrane penetration, involving fimbriae-mediated adhesion and localized proteolytic activity on bacterial cells. More work will be required to extrapolate from these model systems to microbial pathogenesis. We are currently analysing the possible interaction between Pla, plasminogen and basement membrane components other than collagen. 
This work was supported by grants to P. O'T. from the A. Österlund Foundation, the Swedish Society against Rheumatism, the Kock Foundation and the Medical Faculty of Lund University. We are grateful to H. Wolf-Watz for supplying strains, Janos Erdei for helpful advice, to Ingrid Nilsson for cell culture, and to Ragnar Linstedt and Majlis Svensson for in vitro binding assays. We are grateful to Professor T. Wadström for providing a stipend for Dr Kienle (from grant 16X04723 from the Swedish Medical Research Council), and for fruitful discussions.

\section{References}

BachmanN, B. J. (1972). Pedigrees of some mutant strains of Escherichia coli K12. Bacteriological Reviews 36, 525-557.

Beesley, E. D., Brubaker, R. R., JansSen, W. A. \& Surgalla, M. J. (1967). Pesticins. III. Expression of coagulase and mechanisms of fibrinolysis. Journal of Bacteriology 172, 4661-4671.

Bercovier, H., Mollaret, H. H., Alonso, J. M., Brault, J., FANNiNG, G. R., Stiegerwalt, A. G. \& Brener, D. J. (1980). Intraand interspecies relatedness of Yersinia pestis by DNA hybridization and its relationship to Yersinia pseudotuberculosis. Current Microbiology 4, 225-229.

Bölin, I., NoRlander, L. \& Wolf-Watz, H. (1982). Temperatureinducible outer membrane protein of Yersinia pseudotuberculosis and Yersinia enterocolitica is associated with the virulence plasmid. Infection and Immunity 37, 506-512.

BOYLE, M. D. P. (editor) (1990). Bacterial Immunoglobulin Binding Proteins, vol. 1. New York: Academic Press.

Brubaker, R. R. \& Surgalla, M. J. (1962). Pesticins. II. Production of pesticins I and II. Journal of Bacteriology 82, 940-949.

Brubaker, R. R., Beesley, E. D. \& Surgalla, M. J. (1965). Role of pesticin 1 and iron in experimental plague. Science 149, 422-424.

BRUBAKER, R. R. (1984). Molecular biology of the Dread Black Death. ASM News 50, 240-245.

BRUBAKER, R. R. (1991). Factors promoting acute and chronic diseases caused by Yersiniae. Clinical Microbiology Reviews 4, 309-324.

Coleman, D. C. \& Foster, T. J. (1981). Analysis of the reduction in expression of tetracycline resistance determined by transposon $\mathrm{Tn} 10$ in the multicopy state. Molecular and General Genetics 182, 171-177.

Emödy, L., HeesemanN, J., Wolf-Watz, H., Skurnik, M., KaPPERUD, G., O'TOOLE, P. \& WADSTRÖM, T. (1989). Binding to collagen by Yersinia enterocolitica and Yersinia pseudotuberculosis: evidence for yop $A$-mediated and chromosomally encoded mechanisms. Journal of Bacteriology 171, 6674-6679.

Ferber, D. M. \& BRUbaKer, R. R. (1981). Plasmids in Yersinia pestis. Infection and Immunity 31, 839-841.

Filip, C., Fletcher, G., WulfF, J. L. \& Earhart, C. F. (1973). Solubilization of the cytoplasmic membrane of Escherichia coli by the ionic detergent sodium lauryl sarcosinate. Journal of Bacteriology $115,717-722$.

Finlay, B. \& FalKow, S. (1990). Salmonella interactions with polarized human intestinal Caco-2 epithelial cells. Journal of Infectious Diseases 162, 1096-1106.

Glanville, R. W., Qian, R., Siebold, B., Risteli, J. \& Kuhn, K. (1985). Amino acid sequence of the $\mathrm{N}$-terminal aggregation and cross-linking region (7S domain) of the alpha 1(IV) chain of human basement membrane collagen. European Journal of Biochemistry 152, 213-219.

GlanviLle, R. W. (1987). Type IV collagen. In Structure and Function of Collagen Types, pp. 43-79. Edited by R. Mayne \& R. E. Burgeson. London: Academic Press.

Goguen, J. D., Sodeinde, O., Quan, T. \& Youdi, B. (1990). Role of the pla gene in the virulence of Yersinia pestis. Symp. Molec. Biol. Yersiniae: A Model for Gram-negative Pathogenesis. 19th Annual meeting UCLA Symp. Molec. Cell Biol., Frisco, Color., USA, Feb. 22-27, 1990. Journal of Cellular Biochemistry (Suppl.) 14C, 177.

Heesemann, J., Algermissen, B. \& Laufs, R. (1984). Genetically manipulated virulence of Yersinia enterocolitica. Infection and Immunity 46, 105-110.
Helfman, D. M., Feramisco, J. R., Fiddes, J. C., Thomas, G. P. \& HUGHES, S. H. (1983). Identification of clones that encode chicken tropomyosin by direct immunological screening of a cDNA expression library. Proceeding of the National Academy of Sciences of the United States of America 80, 32-35.

Hull, R. A., Gill, R. E., Hsu, P., Minshew, B. H. \& Falkow, S. (1981). Construction and expression of recombinant plasmids encoding type 1 or D-mannose-resistant pili from a urinary tract infection Escherichia coli isolate. Infection and Immunity 33, 933-938.

IsH-HorowICZ, D. \& BURKE, J. F. (1981). Rapid and efficient cosmid cloning. Nucleic Acids Research 9, 2989-2993.

KarLsson, K.-A. (1987). Preparation of total non-acid glycolipids for overlay analysis of receptors for bacteria and viruses and for other studies. Methods in Enzymology 138, 212-220.

LAEMmLI, U. K. (1970). Cleavage of the structural protein during the assembly of the head of bacteriophage T4. Nature, London 227, 680685 .

Lahteenmaki, K. \& Korhonen, T. K. (1991). $t$-PA-mediated plasminogen activation on fimbriate Salmonella. FEMS Symposium Abstracts, Molecular Recognition in Host-Parasite Interactions: Mechanisms in Viral, Bacterial and Parasite Infections, 5-7 August 1991, Porvoo, Finland, p. 28.

LEFFLER, H. \& SvanBORG-EDÉN, C. (1981). Glycolipid receptors for uropathogenic Escherichia coli on human erythrocytes and uroepithelial cells. Infection and Immunity 34, 920-929.

Linstedt, R., Larson, G., FalK, P., Jodal, U., Leffler, H. \& SvanBorG, C. (1991). The receptor repertoire defines the host range for attaching Escherichia coli strains that recognize Globo-A. Infection and Imunity 59, 1086-1092.

McDonough, K. A. \& Falkow, S. (1989). A $Y$. pestis-specific DNA fragment encodes temperature-dependent coagulase and fibrinolysin-associated phenotypes. Molecular Microbiology 3, 767-775.

Nowicki, B., Holthöfer, H., SaRaneva, T., RHEN, M., VäIsÄNENRHEN, V. \& KORHONEN, T. K. (1986). Location of adhesion sites for P-fimbriated and for O75X-positive Escherichia coli in the human kidney. Microbial Pathogenesis 1, 169-180.

OFEK, I. \& ShARON, N. (1990). Adhesins as lectins: specificity and role in infection. In Current Topics in Microbiology and Immunology 151, Bacterial Adhesins, pp. 91-113. Edited by K. Jann \& B. Jann. Berlin: Springer-Verlag.

OWEN, P. (1985). Crossed immunoelectrophoresis in the study of outer membrane antigens. In Enterobacterial Surface Antigens: Methods for Molecular Characterisation, pp. 207-242. Edited by T. K. Korhonen, E. A. Dawes \& P. H. Makela. Amsterdam: Elsevier.

Parkkinen, J. \& Korhonen, T. K. (1989). Binding of plasminogen to Escherichia coli adhesion proteins. FEMS Microbiology Letters 250, 437-440.

Portnoy, D. A., Moseley, S. L. \& Falkow, S. (1981). Characterization of plasmids and plasmid-associated determinants of Yersinia enterocolitica pathogenesis. Infection and Immunity 31, 775-782.

Portnoy, D. A., Blank, H. F., Kingsbury, D. T. \& Falkow, S. (1983). Genetic analysis of essential plasmid determinants of pathogenicity in Yersinia pestis. Journal of Infectious Diseases 148, 297-304.

Portnoy, D. A., Wolf-Watz, H., Bölin, I., Breeder, A. B. \& FALKow, S. (1984). Characterization of common virulence plasmids in Yersinia species and their role in expression of outer membrane proteins. Infection and Immunity 43, 108-114.

PriDmore, R. D. (1987). New and versatile cloning vectors with kanamycin resistance marker. Gene 56, 309-312.

Protsenko, O. A., Anisimov, P. I., Mozharov, O. T., Konnov, N. P., Popov, Y. A. \& Koxushixin, A. M. (1983). Detection and characterization of Yersinia pestis plasmids determining pesticin I, fraction I antigen and "mouse" toxin synthesis. Genetika 19, 10811090.

RosQvist, R., Skurnik, M. \& Wolf-Watz, H. (1988). Increased virulence of Yersinia pseudotuberculosis by two independent mutations. Nature, London 334, 522-525.

Sambrook, J., Fritsch, E. F. \& Maniatis, T. (1989). Molecular Cloning: A Laboratory Manual, 2nd edn. Cold Spring Harbor, NY: Cold Spring Harbor Laboratory. 
SCATCHARD, G. (1949). The attraction of proteins for small molecules and ions. Annals of the New York Academy of Sciences 51, 660672.

SchWarz, U., Schuppan, D., Oberbaumer, I., GlanVille, R. W., TIMPL, R. \& KUHN, K. (1986). Structure of mouse type IV collagen. European Journal of Biochemistry 157, 49-56.

Sodeinde, O. A., Sample, A. K., Rubaker, R. R. \& Goguen, J. D. (1988). Plasminogen activator/coagulase gene of Yersinia pestis is responsible for degradation of plasmid-encoded outer membrane proteins. Infection and Immunity 56, 2749-2752.

SodeInde, O. A. \& GoGUen, J. D. (1988). Genetic analysis of the 9.5kilobase virulence plasmid of Yersinia pestis. Infection and Immunity 56, 2743-2748.

Sodeinde, O. A. \& Goguen, J. D. (1989). Nucleotide sequence of the plasminogen activator gene of Yersinia pestis: relationship to ompT of Escherichia coli and Gene $E$ of Salmonella typhimurium. Infection and Immunity 57, 1517-1523.

SPIRO, R. G. \& SPIRO, M. J. (1971). Studies on the biosynthesis of the hydroxylysine-linked disaccharide unit of basement membranes and collagens. Journal of Biological Chemistry 246, 4899-4909.

Vesikari, T., Nurmi, T., Maki, M., Skurnix, M., Sundquist, C., Granfors, K. \& Gronroos, P. (1981). Plasmids in Yersinia enterocolitica serotypes $O: 3$ and $O: 9$ : correlation with epithelial cell adherence in vitro. Infection and Immunity 33, 870-876.

Virkola, R., Raunio, T., Parkkinen, J. \& Korhonen, T. K. (1991). Basement membrane binding and plasminogen activation by $\mathrm{S}$ fimbriate Escherichia coli. FEMS Symposium Abstracts, Molecular Recognition in Host-Parasite Interactions: Mechanisms in Viral, Bacterial and Parasite Infections, 5-7 August 1991, Porvoo, Finland, p. 36.

Wolf-Watz, H., Portnoy, D., Bölin, I. \& Falkow, S. (1985). Transfer of the virulence plasmid of Yersinia pestis to Yersinia pseudotuberculosis. Infection and Immunity 48, 241-243.

Yanisch-Perron, C., Vieira, J. \& MEssing, J. (1985). Improved M13 phage cloning vectors and host strains: nucleotide sequence of the M13mp18 and pUC19 vectors. Gene 33, 103-119. 